\title{
CLOUD AND ONTOLOGY BASED KNOWLEDGE COLLABORATION - A DIGITAL OIL FIELD INITIATIVE
}

\author{
Piyush Kumar Pandey ${ }^{1}$, Chhiteesh Rai $^{2}$, Sanju Mishra ${ }^{3}$ \\ ${ }^{I}$ Department of Civil Engineering, Teerthankar Mahaveer University, Moradabad, U.P \\ ${ }^{2}$ Department of Computer Science Engineering, Global Group of Institution, Lucknow, U.P \\ ${ }^{3}$ Department of Computer Applications, Mahaveer University, Moradabad, U.P
}

\begin{abstract}
Continuous increase in oil pricing is not only causing difficulties to consumer but the imbalance in demand and supply is impacting the producer and refineries also. Consumer may adjust the demand dynamically as per the price fluctuation but oil major cannot change the production so dynamically. The recommended solution is the latest technology which could optimize the production, meeting the increasing but fluctuating demand at reasonable production price. Continuous increasing in oil prices and demand for crude, the hydrocarbon industry is serious in reaching to its full potential for value creation unless it is not developing the technological innovation. The emerging solution is Cloud based intelligent energy solution. Cloud based smart oil filed engineering is one of the initiative where the oil fields are mathematically modelled as a process industry with unpredictable feed (production). Real time engineering visualization and geospatial scientific computing integration on mobile system is major challenge. Cloud technology has opened an unrestricted universe for Hydrocarbon industry. Cloud Computing led Digital Oil Field is business-centric engineering solutions which has empowered the oil majors to optimize the resources, decreased infrastructure cost, ubiquitous access to business-centric integrated solution, easy engineering visualization and flexible business modelling, ultimately resulting reduction in the production cost of oil \& gas.
\end{abstract}

The cloud based solution is hired on demand service provides robust security, business, modelling, engineering solution, real time visualization, market analytics and management controls on smart mobile device. This paper talks about the case study of a cloud based application (name - EICEbox) helping oil companies solving the complex engineering problem and providing the knowledge collaboration platform to oil and gas companies.

Keywords-Cloud Computing, Cloud Ontology, Digital Oil field, Engineering Knowledge Management

\section{INTRODUCTION}

Exploration and production companies have huge planned fund for data acquisition. This fund have grown multi fold in case of real time data acquisition as it facilitate the operating companies to make operational decisions immediately in accordance with investment and production dynamics. The implementation of sophisticated IT infrastructure takes its own sweet time; while the mobile based cloud computing extends the decision layer to operating companies in reducing the idle time of very expensive equipments.

Oil and gas industry has reluctance in moving to new information technology as this industry is driven by engineering rather than with typical IT automation so just "just-in-time" engineering data with scientific analytics is the demand of hydrocarbon industry. It is difficult to believe, but the reality is that the oil \& gas industry takes real-time decisions on even daily basis, every day, on multimillion-dollar projects comprising new field development, managing the asset, and engineering visualization. The hydrocarbons demand will continue to increase to approximately 100 million barrels per day by 2015. Exploring the new fields has its own limitation. The production optimization and new technology to convert the non-economic field to economically producing field is the only solution to meet the growing demand. Shortage of skilled professionals and billion-dollar of investment towards new developments is another challenge. The unique phenomenon of this industry is that no one shares the engineering intelligence and domain knowledge. Operating in knowledge silos is another big challenge and it can be only addressed through implementation of appropriate knowledge management system $[1,2]$.

Oil \& Gas Industry has realized the importance of "Cloud computing based Digital Oil Field technology [3]" as it helped dropping the infrastructure cost and helped industry the global access of business applications and flexible engineering models on demand. Service on Demand offers the ideal combination of technology and services which extended the easy hand to oil and gas industry players to convert their cloud strategy into reality. Private and hybrid cloud solutions has given the data ownership confidence to oil industry. 


\section{CLOUD TECHNOLOGY IN OIL GAS}

\section{INDUSTRY}

Oil and gas industry is sailed by engineers and geologists. They have huge spending allocation at their disposal. The IT function is always in supporting role and generally gets the back seat. IT department more or less focus in data management, security and communication. Exploration Department wants the quick 3D surface and sub-surface geographical data visualization, while the reservoir engineer wants to go for the reserve modelling. Drilling department wants the real time data acquisition and engineering visualization. Production department which commands the organization has main objective of optimizing the production.

The immediate burning desire of hydrocarbon industry is near better, economical, secure, real time petroleum engineering collaboration of all the departments and real time production analytics. The solution is knowledge based engineering [4], where cloud computing pays vital role. It is estimated that the cloud based well monitoring and reservoir imaging and management technologies could expand global oil reserves by 135 billion barrels by 2015 , and reduce costs by $15 \%$ to $25 \%$.

Followings are the typical spending in an oil company.

Table 1

\begin{tabular}{|l|l|l|}
\hline $\begin{array}{l}\text { S. } \\
\text { No }\end{array}$ & Segment & $\begin{array}{l}\text { Spending in } \\
\text { US \$ per } \\
\text { barrel of oil }\end{array}$ \\
\hline 1 & $\begin{array}{l}\text { IT for seismic processing and other } \\
\text { geological, geophysical }\end{array}$ & 0.10 \\
\hline 2 & Typical technical applications & $\$ 0.10$ \\
\hline 3 & Finance and accounting systems & $\$ 0.05$ \\
\hline 4 & $\begin{array}{l}\text { Hardware and communication \& } \\
\text { servers }\end{array}$ & $\begin{array}{l}\text { Real time engineering application, } \\
\text { scientific visualization,mobile device } \\
\text { based engineering visualization and } \\
\text { cloud computing }\end{array}$ \\
\hline 5 & Total upstream energy IT spending & \\
\hline
\end{tabular}

Cloud computing based digital oil field encompasses a way to increase capacity and added capabilities on the fly without investing in new infrastructure, training new personnel, or licensing new software. It allow Oil companies to capture and analyse the engineering data at greater frequency, from all parts of entire oil\& gas value chain (planning to production to transportation) and analyse it in real or near-real time by availing the service of pay-peruse.

The Cloud Computing has economize the engineering operation of Oil \& Gas industry significantly as in a cloud computing system, the local computers no longer have to do the heavy data lifting when it comes to running the applications. The network of computers that make up the cloud handles them instead. Hardware and software demands on the user's side decrease. The only thing the user's computer needs to be able to run is the cloud computing systems interface software, which can be as simple as a Web browser, and the cloud's network takes care of the rest.

Cloud computing will not be able to compute their own computer, but it can shift their programs and data to the Clouds consisting of computation and storage utilities by third party.

\section{EICEBOX}

Cloud computing is the wave of the future. EICEbox [5] is a cloud-based engineering platform for Oil \& Gas knowledge collaboration [6]. It is developed combining the powerful engineering computation algorithms, cloud based corporate data model, informal knowledge model and web-based user interface leveraging the advance could technology to enable the applicant to use the technology as and when required.

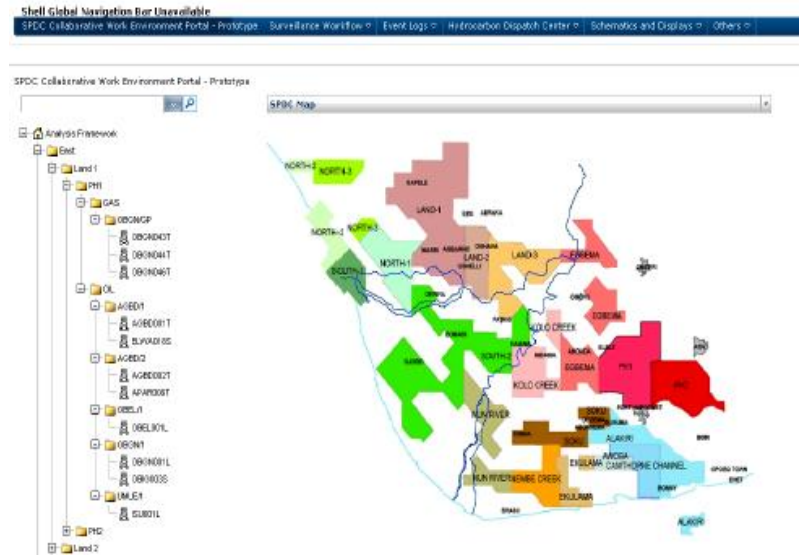

Fig: 1

EICEbox has multi instance, flex tenancy been deployed on cloud since 2010. The application has following primary components:

1. 1. It provides an engineering framework for realtime Integration of process-sourced data, other structured information, and tacit knowledge in meaningful ways; and advanced engineering collaborative platform for production predictive analysis.

2. A proprietary computational engine incorporating a comprehensive set of classical petroleum engineering algorithms for the design and analysis of oil and gas production, and includes solutions in the areas of multiphase flow, Pressure Velocity Temperature (PVT) analysis, heat transfer analysis, reservoir engineering, Oil \& Gas transport network (gathering system) analysis, transient flow modelling and engineering intelligence collaboration.

3. An SQL Azure database hosted on cloud server for storing configuration and operational data for operational equipments comprising; pumps, compressors, motors, tubing, casing, etc. 
4. An intuitive workflow-driven user interface is developed to model the operation of production.

5. The cloud based application is smart enough that it can be executed on smart mobile and hand held devices. This capability of cloud computing has powered operator to monitor \& control the well performance from anywhere.

6. OCloud collaboration provides users to share the engineering state and knowledge resulting lowering time to resolve the well related issues. It allows authorized user to share data, algorithms, and engineering design for production field planning, and real-time operational analysis.

7. Complex petroleum engineering computation related to planning and design simulation.

8. Knowledge processing chain and formal knowledge model to provide engineering intelligence to result.

\section{Cloud Based Digital Dashboard\& Knowledge \\ Management:}

The biggest drives today for an oil and gas company to go for cloud based architecture is to coordinate and integrate data, real time activities, performance of equipments and knowledge on single dashboard. Single application facilitates top management to an engineer analyse the planned data with real production data. It facilitate user to take deep dive in data and scientifically analysis deviation in the results and accordingly the operation can be fine-tuned see fig. $2 \&$ fig 3 .

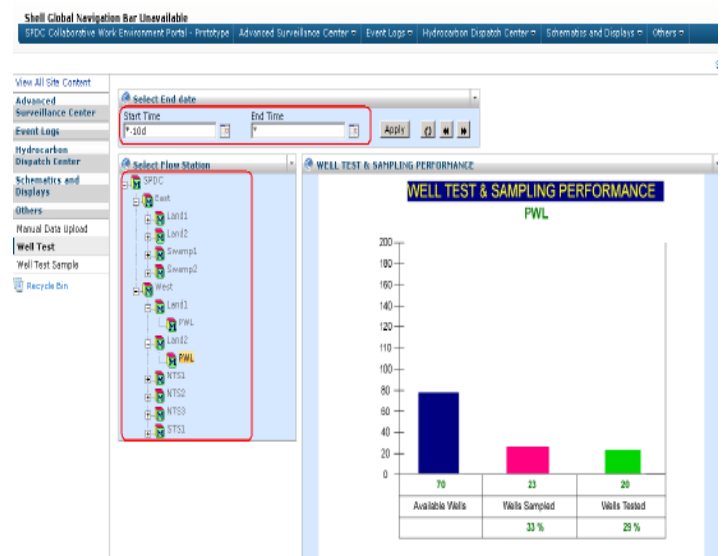

Fig: 2

Cloud based knowledge management application [7] is decision backbone for CEO and CFO. They can get the near real time performance of oil filed operation status anytime, anywhere and if desired they can go in the detail investigation to pinpoint which individual factor is impacting the business. The ultimate mission of knowledge management module is to consolidate organizational skills, knowledge and experience under single system and make it available to every individual.

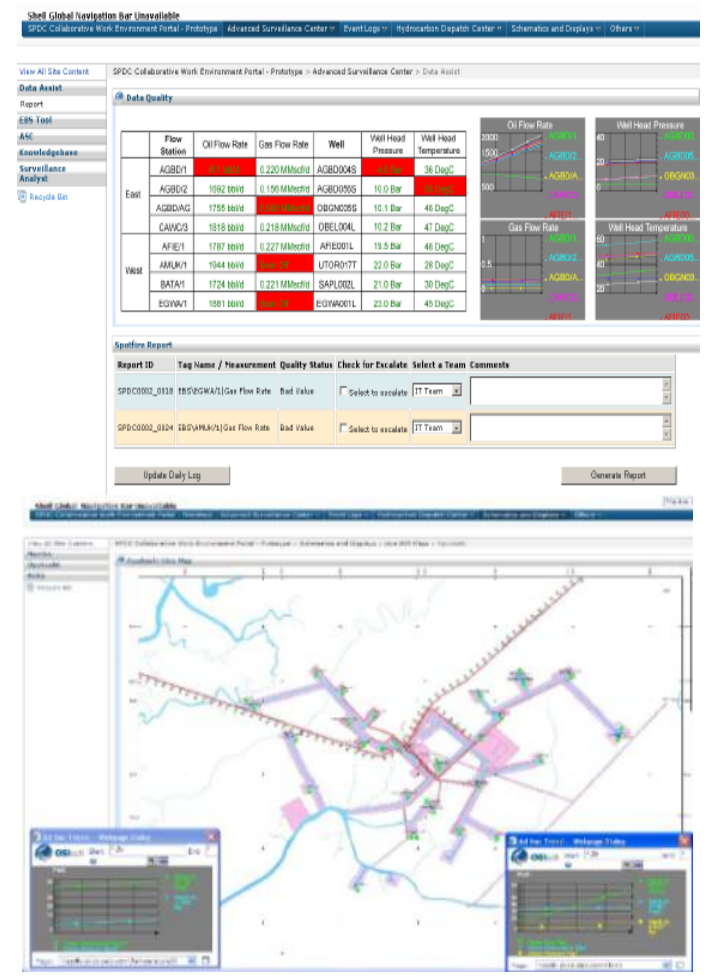

Fig: 3

\section{CLOUD ONTOLOGY}

Ontology can be an alternate to provide Meta information for describing semantics of data [7]. It facilitates a shared understanding of a domain of interest to support communication among human and machines [8]. Ontologies are represented by a set of concepts and relationship between concepts, and also be applied into information retrieval to interact with the user queries [9].There are three categories in Cloud Computing; they are generally divided into three different levels (IaaS, PaaS, and SaaS [10]) see Fig. 4.Infrastructure as a Service (IaaS) supply hardware, software, and equipments to deliver software application environments with a resource usage-based pricing model. Platform as a Service (PaaS) offers a high-level integrated environment to build, test, and deploy custom applications. Generally, developers will need to accept some restrictions on the type of software they can write in exchange for builtin application scalability.

Software as a Service (SaaS) delivers special-purpose software that is remotely accessible by consumers through the Internet with a usage-based pricing model.

Cloud Computing Ontology has categorised in two parts such as: functional cloud service configuration parameters and non-functional cloud service configuration parameters. The functional cloud parameters are involve to represent the Cloud Resource that is further has three types, IaaS, PaaS, SaaS as in fig 4. 


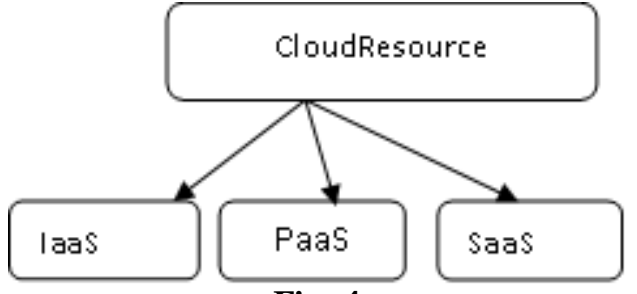

Fig: 4

\section{RELATED WORK}

Author presented a smart use of taxonomy [13]for engineering knowledge management and integration of knowledge reservoir with near real time engineering operation of oil \& gas production field.

Number of Cloud providers provides branded calculators,such as Amazon [11] Azure [12], andGoGrid, for service leasing cost calculation. While, it isnot easy for users to generalize their requirements to fit different service offers let alone computing and comparing costs.

An industry accepted cloud based production optimization and engineering intelligence collaboration applications [14] is available for commercial use.

\section{CONCLUSION}

The adoption of cloud based engineering knowledge $\&$ field intelligence collaboration over smart mobile devices resulting considering reduction in the costs and increase in profitability, simply by integrating engineering operation, real time production monitoring, finance, human capital management, supply chain, field asset management and project management. It is affordable, flexible and takes lesser time to implement. The cloud based engineering collaboration solution integrates and automate every engineering, business and corporate data in one system.

\section{REFERENCES}

[1] Allee, V. (2003), The Future of Knowledge, Burlington, MA: Butterworth-Heinemann, 2003.

[2] Guarino, N. (ed.), 1998, Formal Ontology information systems, IOS Press, Amsterdam.

[3] http://www.slb.com/resources/technical_papers/soft ware/128766.aspx

[4] Borst, P., 1997, Construction of EngineeringOntologies, Ph.D. thesis, CTIT, Enschede, TheNetherlands

[5] http://www.EICEinternational.com

[6] Ahmed, S., Kim, S., Wallace, K. M., (2005). A Methodology for Creating Ontologies forEngineering Design, In Proc. Of ASME DTM, 2005, DETC2005-84729

[7] Firestone, J. M. (2000a), "Enterprise Knowledge Portals: What They Are and What They Do," Knowledge and Innovation: Journal of the KMCI, Vol. 1, no. 1, pp. 85-108.

[8] C. N. Hoefer and G. Karagiannis, Taxonomy of CloudComputing Services, in GLOBECOM
Workshops (GC Wkshps), 2010 IEEE, 2010, pp. $1345-1350$

[9] Heiner Stuckenschmidt, Ontology-based information sharing in weekly structured environments, Ph.D. thesis, AI Department, Vrije University Amsterdam, 2002.

[10] Ian Foster, Yong Zhao, Ioan Raicu, Shiyong Lu, Cloud Computing and Grid Computing 360-Degree Compared,

[11] Amazon Price Calculator, http://calculator.s3.amazonaws.com,

[12] Windows Azure Calculator, http://www.windowsazure.comaccessed June 2012.

[13] Foundation for intelligent physical agents. FIPA Ontology Service Specification, http://www.fipa.org/specs/fipa00086/ XC00086D.html, FIPA 2001.

[14] http://eice.cloudapp.net/ 